\title{
John Adams and CERN: Personal Recollections
}

\author{
G. Brianti \\ Formerly CERN, 5 Chemin des Tulipiers, \\ 1208 Geneva, Switzerland \\ g_brianti@bluewin.ch \\ D. E. Plane \\ CERN, 1211 Geneva 23, Switzerland \\ david.plane@cern.ch
}

\begin{abstract}
By any standards, John Adams had a most remarkable career. He was involved in three important, emerging technologies, radar, particle accelerators and controlled fusion, and had an outstanding impact on the last two. Without a university education, he attained hierarchical positions of the highest level in prestigious national and international organizations. This article covers the CERN part of his career, by offering some personal insights into the different facets of his contributions to major accelerator projects, from the first strong-focusing synchrotron, the PS, to the SPS and its conversion to a proton-antiproton collider. In particular, it outlines his abilities as a leader of an international collaboration, which has served as an example for international initiatives in other disciplines.
\end{abstract}

Keywords: Accelerators; CERN; PS; SPS; John Adams; international organizations.

\section{Introduction}

The eminent role played by John Adams in the field of particle accelerators on the international scene, in particular at CERN, has been well documented in a number of excellent publications. In his honor, CERN introduced a series of annual lectures, the John Adams Memorial Lectures, which have continued to this very day. The inaugural lecture in 1985, covering the whole of his career, was delivered by the visionary Prof. Edoardo Amaldi [1], who appointed Adams in 1953. It was followed 24 years later (2009) by E. J. N. Wilson [2], who centered his talk on his personal experience of working with Adams. Michael Crowley-Milling published in 1993 [3] a complete biography of this exceptional personality and, in 1977, M. Goldsmith and E. Shaw wrote Europe's Giant Accelerator, describing the design and construction of the SPS complex [4].

While referring to them, we intend to complement these publications by giving an account of our own personal experience with him, starting from the working ambiance in the early CERN during the design and construction of the PS and, later on, of the SPS. We then extend the review of his achievements to developments, such as the protonantiproton project [5], which led to the discovery of the $\mathrm{W}$ and $\mathrm{Z}$ bosons, and later LEP and the LHC [6]. In addition, a section is devoted to the SPS experimental areas, which have served a large community of particle physicists for more than 30 years.

Giorgio Brianti, the primary author, wrote the sections dealing with the early days of CERN and the construction of the PS (Secs. 2-4), the ones dealing with the SPS story and construction (Secs. 5 and 6), and the one on further developments (Sec. 8). David Plane, the second author, wrote Sec. 7, on the SPS experimental areas.

John Adams also made major contributions to thermonuclear and plasma research - these are well described in Refs. 1-3.

\section{CERN...upon Arve ${ }^{a}$}

On a sunny, late September afternoon in 1954, a few hours after my arrival in Switzerland, I reached

\footnotetext{
${ }^{\mathrm{a} A r v e, ~ t h e ~ s e c o n d ~ G e n e v a ~ r i v e r, ~ i s ~ n e a r ~ t h e ~ P h y s i c s ~ I n s t i t u t e, ~ w h e r e ~ t h e ~ e a r l y ~ P S ~ D i v i s i o n ~ w a s ~ h o u s e d . ~}$
} 
the terrace of the Physics Institute in downtown Geneva for the classical five o'clock tea with some new colleagues. CERN, I learned, had just become an official organization after the ratification of the founding treaty by a sufficient number of European parliaments. Someone guided me toward a tall, handsome and distinguished-looking man with a pipe in his hand, whispering in my ear, "Follow me, I'll introduce you to the boss." John at that time was only 34 , but had a very natural authority. To say that we had a conversation would be an exaggeration because of my still uncertain English, but I understood that I was assigned to the Magnet Group. After this first encounter, I moved down to the barracks, where the entire PS Division was housed, waiting for the Meyrin site to became available. The job was to build the $25 \mathrm{GeV}$ Proton Synchrotron (PS), the initial raison-d'être of CERN.

In the preparatory phase (1952-1953), Odd Dahl, a Norwegian professor from Bergen, had been the PS project leader, while Frank Goward, who had come from Harwell with John Adams and Mervyn Hine, was his deputy. Finally, Dahl renounced going to Geneva and Goward took on the job. In the spring of 1954, Goward died suddenly and John became the PS leader. John and Hildred Blewett from BNL also joined the PS team to help with the design [3]. Most of the other members were very young applied physicists or engineers coming straight from university, who in general had heard the word "synchrotron" for the first time in connection with CERN.

I soon found out that the Magnet Group had the task of designing and producing the magnetic system, which would guide and focus the particles around the $628 \mathrm{~m}$ ring.

The Group Leader was Colin Ramm, an able Australian, who worked closely with Cornelius (Kees) Zilverschoon, a clever and extroverted Dutchman who was Head of the Engineering Group. The second-hand barracks, acquired from the Swiss army as war remnants, included offices and a small electronics laboratory, in addition to which a small assembly hall was available, where magnet and other sizeable models were installed for measurements and development work. At that time, Lorenzo Resegotti, Claude Germain, Bastian de Raad, Dirk Neet and Jean Pierre Stroot were also members of the Group.

The initial plan was to build a weak-focusing synchrotron of $10 \mathrm{GeV}$, a scaled-up version of the Cosmotron, but the recent invention of the strong-focusing principle by Courant, Livingston and Snyder (1952) [7] prompted CERN to take the bold decision to construct a $25 \mathrm{GeV}$ (later $28 \mathrm{GeV}$ ) machine based on the new principle, but at the same cost. One of the great novelties of strong-focusing synchrotrons was of course the magnet system, so it was not surprising that it received so much attention. The other novelty was the appearance of the transition energy, requiring a sudden jump in the radio frequency phase during acceleration, when beam stability is lost.

There were also major doubts about the influence of non-linear resonances caused by magnet imperfections. It seemed that this would lead to almost-impossible construction tolerances. E. J. N. Wilson [2] quotes an account of a meeting in Harwell at the end of 1952, prior to the arrival of John Adams in Geneva:

"It was John's job to help resolve the many doubts there still were about this decision to change to alternating-gradient focusing. John Lawson had warned of the dangers of non-linear resonances and Kjell Johnsen had to be persuaded that transition would not be a problem. John and Mervyn Hine studied the non-linear resonances driven by magnet imperfections using $\mathrm{ACE}$, one of the first computers available in the UK. It seemed that because of the high field gradient ( $n$-value) of the first design, magnet construction tolerances would need to be unrealistically tight to avoid these resonances. Hine writes: 'I remember at the end of the Harwell meeting John summarized and took over. He stepped into the authority position and wrote a summary on the blackboard in his wonderfully clear left-hand writing." "

At the time of my arrival, there were still traces of this debate in the form of magnet models with very narrow and sharp pole pieces (looking like two opposing knives) corresponding to $n=(R / B) *$ $(d B / d R)=4000$, with gradients of about $50 \mathrm{~T} / \mathrm{m}$, as in strong quadrupole magnets of a modern separate function FODO lattice. However, in a FODO lattice the quadrupole magnets cover no more than $10-15 \%$ of the total magnetic length, while with combined function magnets the gradient is present over the entire length! The magnet weight was estimated to be only 800 tons for a $30 \mathrm{GeV}$ machine, which, in all probability, would not have worked. Finally, more 
realistically, the $n$ value adopted was 288 for a total magnet iron weight of 3300 tons.

The above reference gives me the opportunity to introduce two other very important persons of the early CERN, Mervyn Hine and Kjell Johnsen. Mervyn, also a British physicist, forming with John the so-called "Harwell twins," was John's "alter ego," especially on scientific and technical grounds, while the Norwegian Kjell was originally an assistant of Prof. Dahl. Both were very competent in many fields. John ran the project by leading two types of regular meetings: the staff meeting attended by all academic colleagues, where progress reports and general information were on the agenda, including of course extensive discussion; and the more restricted Parameter Committee, in which only Group Leaders participated. Being too junior, I participated in only the first type of meeting, where I was very impressed by the intellectual power and the competence of John, Mervyn and Kjell. However, John always had the final word at the end of the meeting by summing up the discussion in a concise and clear way, and with a very natural authority. He gave the impression of being able to promptly appreciate fully the pros and cons of any technical or managerial issue and reach the most appropriate decision.

From the very beginning of CERN, John and his leading team wanted to have complete in-house technical expertise for all machine systems, not only at the academic level but also at all other levels. This coincided with the view of Prof. Edoardo Amaldi [1], who was the Secretary-General (DirectorGeneral) of the provisional organization from 1953 to 1954 and who held the view that the development of CERN should be based on very solid technical expertise, by recruiting not only physicists but also engineers. Indeed, he did just that for a number of Italian engineers, including Franco Bonaudi (the first CERN employee), Mario Morpurgo, Guido Petrucci, Lorenzo Resegotti and myself. Other engineers and technicians were recruited from all over Europe. Locally, almost the entire staff of the mechanical workshop (a dozen or so people) of the neighboring Physics Institute of the University of Geneva were also recruited by CERN. Although this was not popular at the Institute, it provided us with a quite exceptional team of mechanical workers.

Returning to the early work in a common hall, I would like to mention a particular magnet model

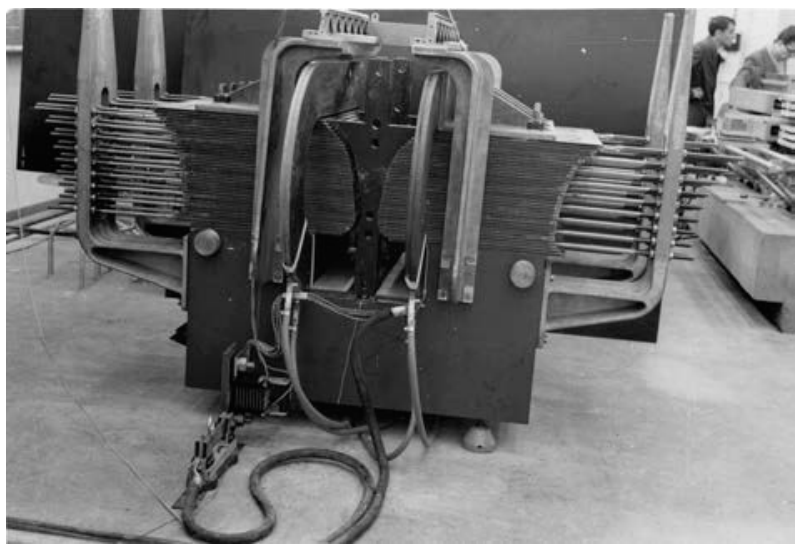

Fig. 1. The adjustable pole model for PS magnet development.

(Fig. 1) used to find the most appropriate profile for the magnet laminations. In a time when computer programs were not yet available, it consisted of a stack of about $1 \mathrm{~cm} \mathrm{C}$-shaped plates perpendicular to the actual final block plane, which could be moved independently of each other by appropriate long screws. Varying the profile of the pole pieces in this way allowed us to determine the optimal profile of the pole pieces. The trouble was that the screws were very hard to move - providing an excellent way to develop our young muscles!

Among the exotic objects in the hall was a mechanical machine with a rotating shaft for cycling current through the magnet model. The rotation of the shaft produced, at appropriate times, the opening and closing of a set of switches. One day Albert Picot, a minister of the local government, who was a strong supporter of CERN, was visiting our provisional quarters, and he walked around the hall accompanied by John. Just when they arrived in front of this machine, which happened to be in operation, something went wrong and a switch suddenly opened under full current, producing a terrifying discharge, which sounded like an explosion. Picot disappeared very quickly, but continued to support CERN... from a distance.

All the machine components were developed in this single assembly hall and our daily work there helped us grow in mutual understanding and promoted friendships. The differences in our national cultures were not obstacles to our working together, but rather a source of mutual enrichment. Most of us were still single, so often we continued to stay 
together outside the normal working hours for outings and weekend trips around Geneva.

The Magnet Group rapidly became stronger and stronger, with the arrival of Simon van der Meer [8], Gunther Plass, Helmut Reich and others. The first job of Simon, who arrived with a high reputation, was to calculate the pole-face windings to be installed on the pole surface for correcting the magnetic field imperfections. It was considered to be a difficult problem, which I and other earlier arrivals were reluctant to tackle. Of course, he was able to solve it in a rather short time using only a mechanically hand-driven calculator.

The well-trained professional mechanical workers were not only skilled according to the best Swiss watch-making tradition, but also inventive and very enthusiastic in their work. They were able to produce masterpieces, particularly for magnetic measurements. I would like to cite two examples: a small plastic turbine driven by compressed air, reaching almost 1000 turns/min for rotating coils used to measure magnetic fields, and a permeameter (Fig. 2) for measuring magnetic steel properties. The latter consisted of three toroidal concentric coils split in the median plane embedded in a plastic structure, which could open and close for the insertion of the steel rings to be measured. It has since become a standard instrument for all subsequent accelerators.

My initial job was the choice of the steel laminations. The choice fell on classical car body steel, which was cheap and, at that time, was produced by many companies in Europe. However, a problem had to be solved: the usual car body steel had too high a coercive force, which would cause too high

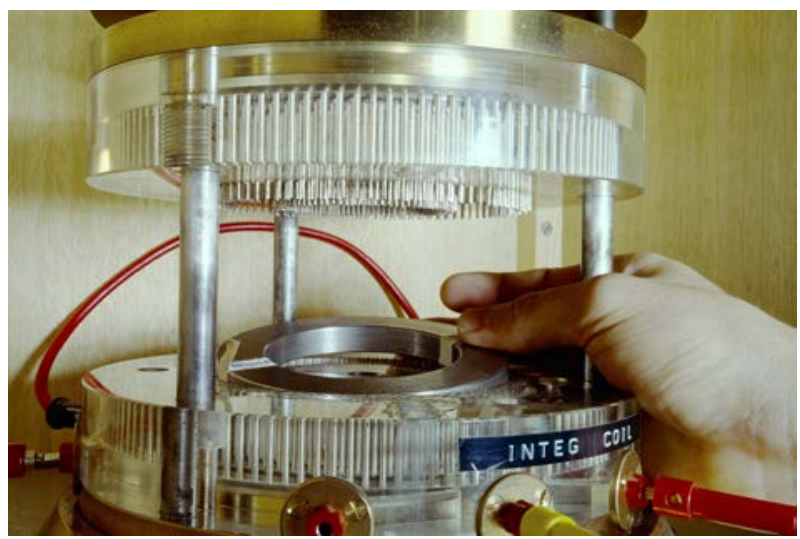

Fig. 2. The original permeameter, developed to measure magnetic steel properties. a magnetic remnant field at injection; moreover, this property varied widely from batch to batch. The high coercive force was due to the very small metallurgical grains, which were required in order to avoid the so-called "orange skin" when laminations were deepdrawn to produce car bodies. I found out in the literature that a rather light final cold work (skin pass) on the laminations, followed by appropriate heat treatment, would increase enormously the grain size and hence reduce considerably the coercive force and the remnant field. An additional important precaution was to stock all the steel laminations in batches, and then select laminations from each batch to produce a block.

In 1956 we moved to the Meyrin site, which at that time was entirely on Swiss territory but adjacent to the French-Swiss border. By choosing this location, the local authorities thought that any possible extension would have to be in France, which indeed happened ten years later for the construction of the Intersecting Storage Rings (ISR) and then, more extensively, for the SPS, LEP and LHC.

\section{PS Construction}

The intense prototype and model work progressed rather rapidly toward a final design, consisting in a magnet system composed of 100 units made up of 10 blocks each (see Fig. 3), mounted on a sturdy common girder and with common coils.

The $1 \mathrm{~mm}$ laminations, punched by very precise dies, were electrically insulated by a sheet of paper glued by a new thermal setting epoxy resin, araldite. After assembly, the blocks had to be heated and then cleaned of the excess polymerized glue by metallic brushes: a terrible job!

Figures 4-6 show the first complete PS magnet unit, a section of the PS ring and a view inside the completed ring.

I mention these technical details to illustrate the care that John wanted to be applied to all aspects of the technical solutions before adopting them. He was aware that building the first European research accelerator based on the brand-new and untested strongfocusing principle was already a considerable risk, which had to be attenuated as much as possible by a very careful and prudent design. Among many, one example of this prudent approach is the circular concrete beam, supported by pillars going down to the 


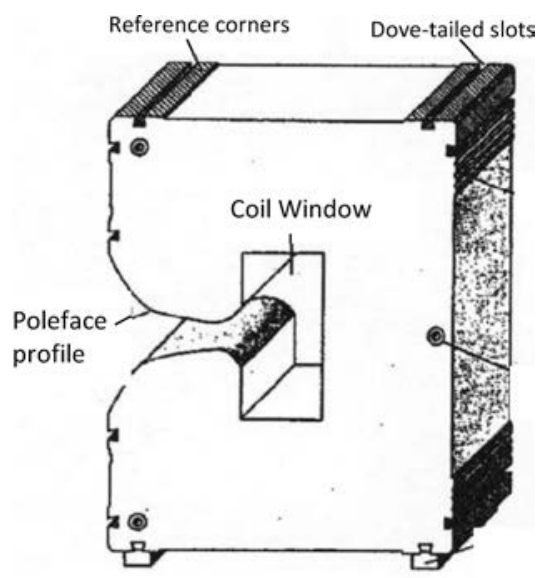

(a) "Open" Block

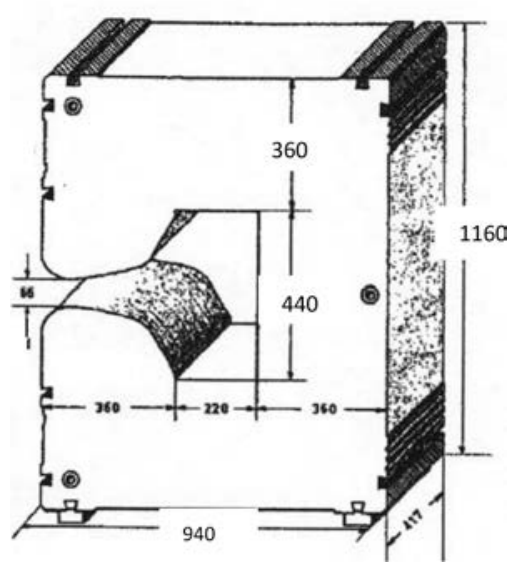

(b) "Closed" Block

Fig. 3. PS "open" and "closed" magnet blocks.

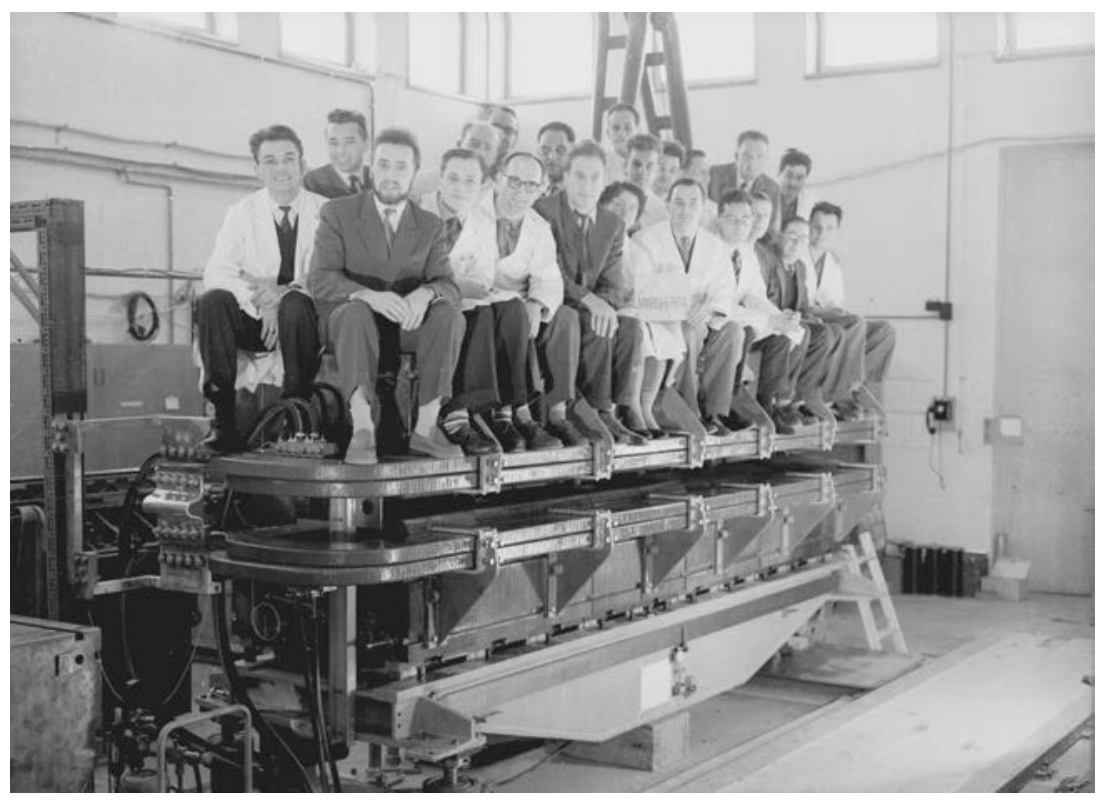

Fig. 4. The first PS magnet unit and its proud builders. The author (G. B.) is in the back row, second from the right.

rock, on which the machine is installed. The temperature of the tunnel is controlled in order to insure a very accurate alignment [3].

This was considered by some people to be "overdesigned" and this opinion tainted the reputation of the CERN accelerator community for some time, especially after the construction of the second large machine, the ISR. Later on John himself showed a much less conservative technical approach when constructing his new machine, the SPS, and, in particular, when he approved and encouraged the adventure of the proton-antiproton project.
Returning to my personal story, I would like to underline another characteristic of John's managerial skills. I was asked to supervise both the production of the steel laminations and of the thousand magnet blocks on the premises of the two chosen firms in Genoa. After an intense preparation, the production of the magnet blocks started, but the first blocks were out of tolerance due to hasty and careless procedures. I warned my bosses in Geneva and I was expecting that they would come to discuss the situation with the firm. Instead I was told, "Write an order on CERN's behalf to stop the production and 


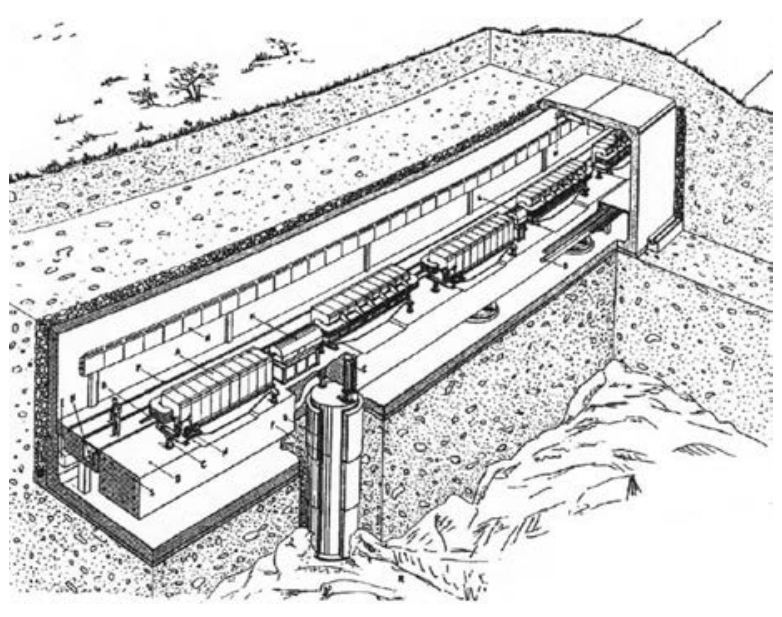

Fig. 5. A section of the PS ring.

go away. Leave a telephone number to call you back when they will intend to follow your instructions." After a few days they called me back and the production restarted following the correct procedure. This confidence in a young person at the beginning of his career marked my ensuing professional life.

The production of the blocks continued according to schedule, so that, at the beginning of 1958, I could return to Geneva. John gave me a new job, this time in the Controls Group, with the responsibility of completing the main control room, which was well behind schedule. In the end we installed it more or less on time, but it certainly did not look like the modern computer-based control centers. All important elements were installed in racks along the walls, with forests of cables connecting them on the front faces. On the central desk there were only telephones, a microphone, and two meters - a voltmeter giving the energy and an ampere meter giving the current pulse by pulse.

The commissioning of the machine and its final success are well documented in the references. The evening of 24 November 1959 will remain forever in our memories as a milestone in our professional lives. We were particularly proud of the fact that the PS started operation six months ahead of the sister machine, the AGS in Brookhaven. Figures 7 and 8 are photographs taken at that time.

Under the guidance of John, we all learned that adopting very sound engineering of any single component and paying extreme attention to tolerances was of paramount importance for the success of the PS. We were taught to tackle technical design and construction on the basis of an attitude which was one of the facets of John's personality, namely "constructive pessimism," just the opposite of "blind optimism." Indeed, John was a pessimist not in a negative way, but in the sense that he believed that nature had no reason to make gifts to accelerator designers. Therefore the correct attitude consisted in understanding the finest details of each problem in order to make a design which left nothing to chance

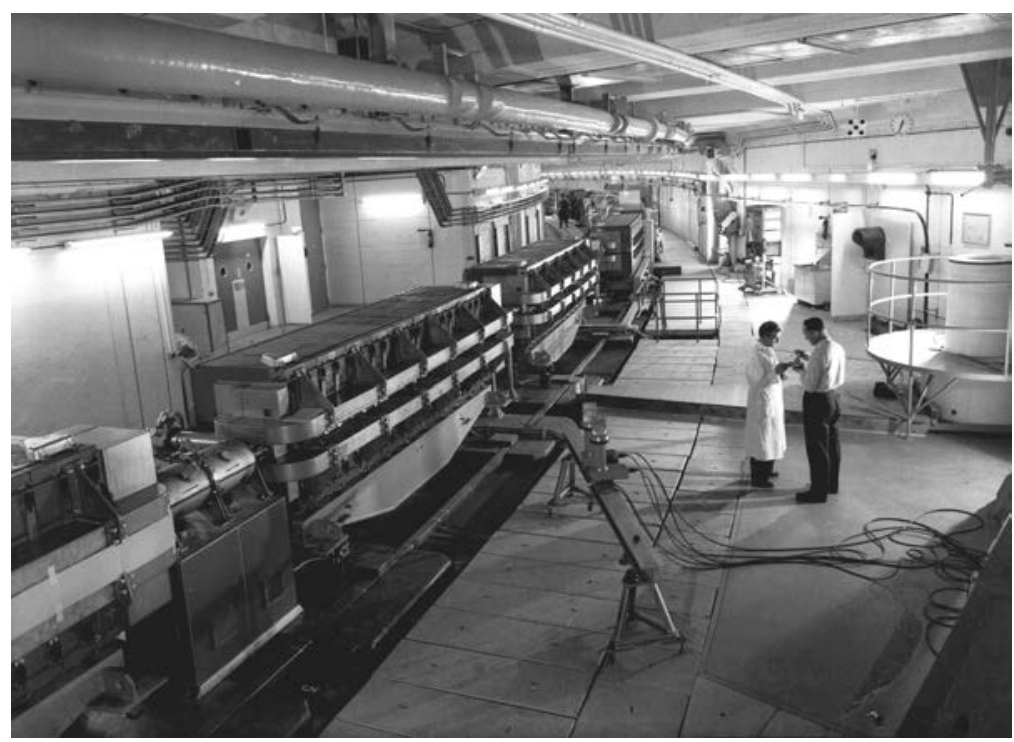

Fig. 6. The PS ring. 


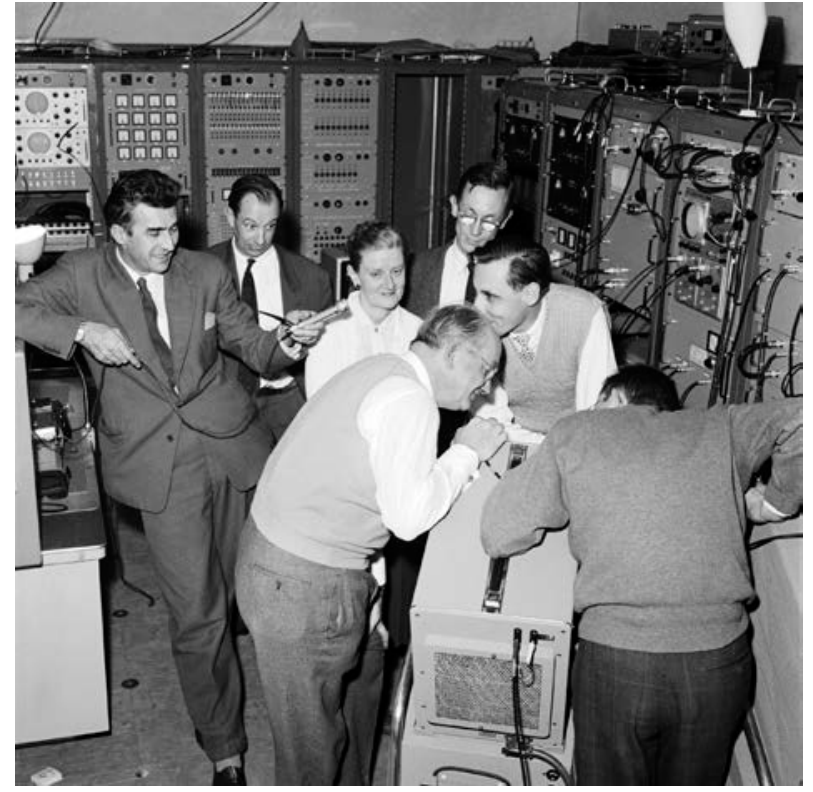

Fig. 7. PS startup, 24 November 1959. From left: Adams, Geibel, Hildred Blewett, Laslett, Schmelzer, Schnell, Pierre Germain.

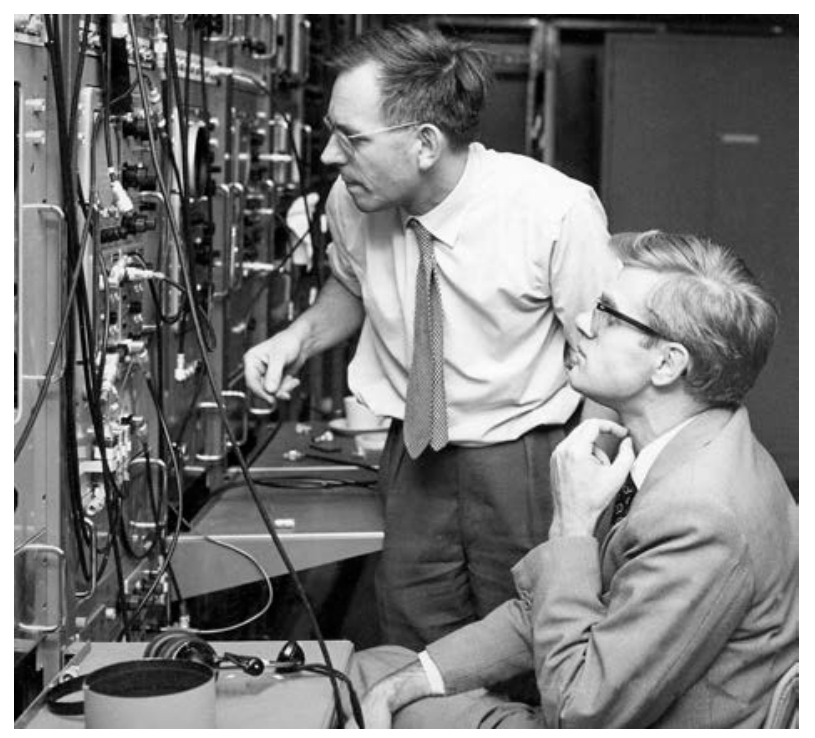

Fig. 8. Mervyn Hine and Kjell Johnsen in the PS control room.

on the way to success. Some people confused this with conservatism and overcautiousness. Later on, based on his experience with the PS, he became more confident about using smaller safety factors and was able to take significant risks in transforming the SPS into a proton-antiproton collider.
It is also interesting to note that John did not publish many articles in well-known scientific or technical magazines. His decisive influence on projects was essentially through decisions after thorough discussion in staff meetings or personal contacts with people responsible for given machine systems. These discussions and decisions are recorded in innumerable minutes of meetings and in a collection of his handwritten personal notebooks. Of course, he also made many reports to official CERN bodies, like the Council and the Scientific Policy Committee.

\section{CERN at a Turning Point}

Already, before the completion of the PS, John decided to go back to England, and in August 1959 he was appointed Director Designate of the newly constituted Culham Laboratory for fusion research. The appointment was to become effective during 1960 , but the tragic accidental death of DirectorGeneral Bakker in an air crash in April 1960 changed the plan. John was named Acting Director-General and soon after Director-General until 1 August 1961, when Viktor Weisskopf could take over as DirectorGeneral.

After a slow start the experimental program around the PS moved ahead, and reflection on future projects got underway. In 1963 the European Committee for Future Accelerators (ECFA) was formed, on which all European physicists were represented, with the scope of deciding which new projects should be adopted. Prof. Edoardo Amaldi was its first Chairman. Two main lines were considered: a proton collider fed by the PS, and a synchrotron of $300 \mathrm{GeV}$ $[2,3,9]$. The construction of the ISR (Intersecting Storage Rings, with $30 \mathrm{GeV}$ proton beams) was approved in December 1965 for completion in 1970, together with the intermediate injector for a tenfold increase in the PS intensity, which later became the Booster. The decision to build the $300 \mathrm{GeV}$ accelerator was postponed, for at least two reasons. The first was financial, in order not to cumulate its cost with that of the ISR, but the second was more fundamental. In fact, it was judged impossible to build it in, or adjacent to, the Geneva site with the classical cut-and-fill method for the construction of the 7-km-long tunnel. It was deemed necessary to establish a new laboratory somewhere in Europe. The Council launched a call to the Member States for 
a new site, which had considerable quantitative success: in a short time, sites were proposed in almost each country, with even more than one in some countries. Of course, this raised several difficulties, such as the cost of the new laboratory, the role of the existing one in Geneva and the actual choice of the new site $[2,3,9]$.

Meanwhile, in the US at the end of 1966, it was decided to establish the new National Accelerator Laboratory (NAL) in Batavia near Chicago and build the so-called $200 \mathrm{BeV}$ machine. Soon after, in 1967, R. R. Wilson was appointed as Director and transformed the project into a $200-400 \mathrm{BeV}$ machine based on a separated function focusing scheme [3].

Two years later, in 1969, the CERN Council took the bold decision to call back John Adams and appointed him as Director-General Designate of the new laboratory, yet to be approved $[2-4,9]$. There are no better words than those of John himself to summarize the difficulties:

"Looking back, I think one can discern a number of reasons why our Member States hesitated to reach a decision on the $300 \mathrm{GeV}$ Programme in the form it was presented at that time. In the first place the economic situation in 1969 for science in general and nuclear physics in particular was very different from the ebullient years around 1964 and 1965 when the $300 \mathrm{GeV}$ Programme was first put forward. It was evident that several Member States of CERN and possibly all of them found the cost of the Programme too high compared with their other investments in science and with the growth rates in their total science investments, which had dropped from figures around $15 \%$ per annum in 1965 to a few per cent per annum in 1969. In the second place, the idea of constructing a second European laboratory for nuclear physics remote from the existing one, which had seemed attractive in 1965, looked inappropriate in 1969 , particularly since it implied running down the existing CERN laboratory when the new one got under way. In the third place, so many delays had occurred in the $300 \mathrm{GeV}$ Programme and the American machine was coming along so fast that an eightyear Programme to reach experimental exploitation seemed too long.

Fourthly, it turned out that choosing one site amongst five technically possible sites presented non-trivial political problems for the Member States of CERN." [10].

\section{Preparation of the $300 \mathrm{GeV}$ Project}

Initially with a very small staff (only Ted Wilson was full-time), John started immediately to work on two lines: how to reduce the cost of the project and how to solve the site problem. The existing project was essentially a scaled-up version of the PS with combined function magnets. This design implied that the field on the central orbit could only be about $1.3 \mathrm{~T}$ because the field in the narrower part of the gap cannot exceed 1.8-2.0 T. In a separated function machine, the much higher central field leads to a smaller circumference and hence to a lower cost, or to a higher energy for the same cost. E. J. N. Wilson has given an excellent account of this phase [2]. John adopted the new separated function design, but the problem of the new site remained, including not only the choice among the five technically suitable sites of the final shortlist but also the fate of the existing laboratory in Geneva. At this point, the idea put forward earlier by Colin Ramm of a synchrotron installed in an underground tunnel, albeit of lower energy, was seriously considered. It turned out that the land between the Meyrin site and the Jura mountains at a sufficient depth was made of molasse, a sedimentary rock composed of sandstone and marl, which was relatively easy to excavate by means of a full-size boring machine [3]. The extension of this molasse bed was easily sufficient for a machine diameter of $2200 \mathrm{~m}$, adequate for the wanted energy, at the reasonable depth of about $40 \mathrm{~m}$.

These changes led to a cheaper solution making full use of the existing installations (injectors, a large experimental area) and assuring the future development of the Geneva Laboratory. They also led to the approval of the $300 \mathrm{GeV}$ project, which turned out to be crucial for the subsequent, but unforeseen at that stage, larger projects, LEP and the LHC. Indeed, the question of another laboratory away from Geneva never came up again! Figure 9 shows the President of the CERN Council on the day the $300 \mathrm{GeV}$ project was approved.

I believe that the installation of the laboratory on this unique site over the last 60 years was, and continues to be, a great asset to CERN and has been crucial for its success, not only because, from the 


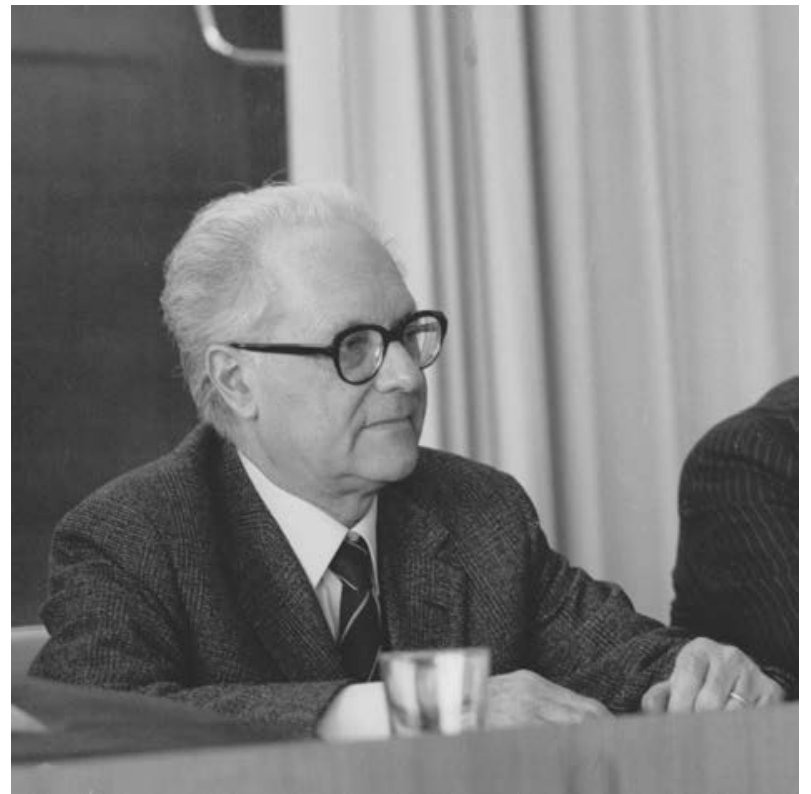

Fig. 9. Professor Edoardo Amaldi, President of the CERN Council, 19 February 1971. The $300 \mathrm{GeV}$ program was approved.

material point of view, it allowed the use and reuse of existing installations, but also because, from the staff point of view, it ensured the continuity and the harmonious evolution of technical expertise.

\section{6. $300 \mathrm{GeV}$ Program}

The $300 \mathrm{GeV}$ program had a duration of eight years, but with the proviso of starting physics experiments at least in the existing West Area in 1976. In addition, there was the idea of the so-called "missing magnet" scheme, consisting in installing all the quadrupole magnets but only half of the dipole magnets in order to start the physics earlier at $200 \mathrm{GeV}$. Later on, one would install the rest of the dipole magnets, realign the machine and reach full energy.

Immediately after the approval, John (appointed Director-General of CERN Laboratory II) started to set up the team for the detailed design and construction of the machine and its experimental areas [1-4]. Of course, he considered accelerator experts not only from CERN but also from other European national laboratories.

Among the CERN staff, the first to be appointed was Bastian de Raad for beam transfer (injection and extraction), followed by Simon van der Meer [8] for the power supplies and Hans Horisberger for mechanical engineering. John also called me to discuss my possible task. At that time I was building the PS Booster, the new $800 \mathrm{MeV}$ injector for the PS, consisting of four superimposed synchrotrons, with the purpose of a tenfold increase in the PS intensity, due for completion in 1972. John asked me to take up the responsibility of the magnet system, which, being one of the most urgent tasks, would have required abandoning immediately the Booster. I felt that this was not appropriate. He understood and proposed to me the less urgent job of the experimental areas, provided that I would participate immediately in the management meetings. Finally, the magnet system was entrusted to Roy Billinge, returning from FNAL.

Other important persons came from outside, namely Hans-Otto Wüster from DESY, who became John's Deputy, Michael Crowley-Milling from Daresbury for Controls, and Robert Lévy-Mandel from Saclay for supervising civil engineering and general installation work. Figures 10 and 11 are photographs taken during the SPS construction phase, and Figs. 12-14 show John in the company of close colleagues.

John adopted the classical tree structure for the management, consisting of groups for the various systems, for the machine layout and for some general tasks. Together John, the Group Leaders, Hans-Otto Wüster, E. J. N. Wilson (for parameters), B. Milman (for planning and budgets) and R. Florent (for

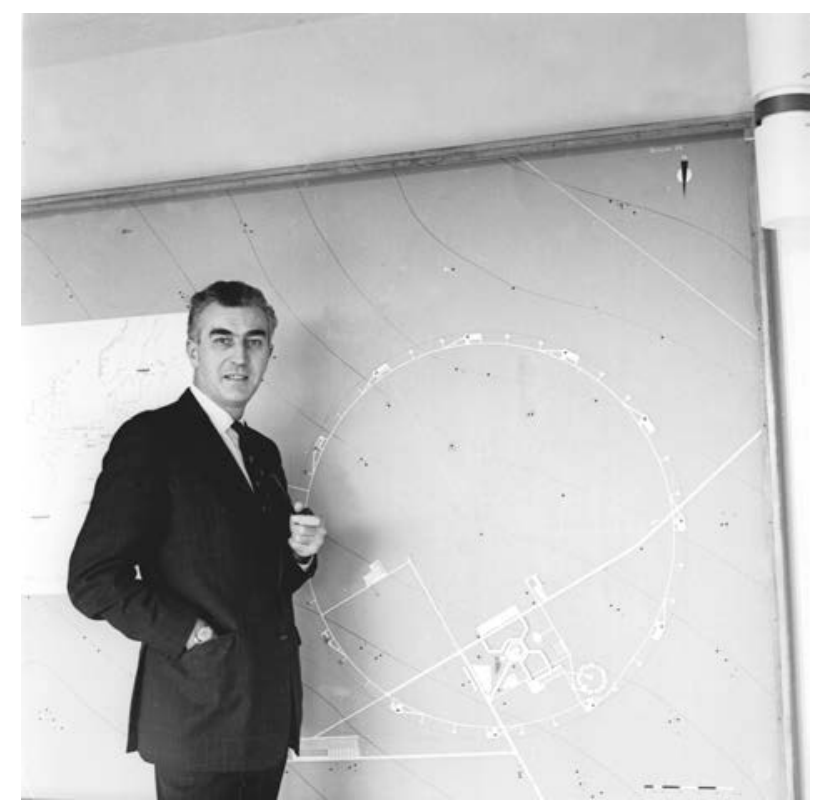

Fig. 10. John Adams in front of an early $300 \mathrm{GeV}$ layout. 


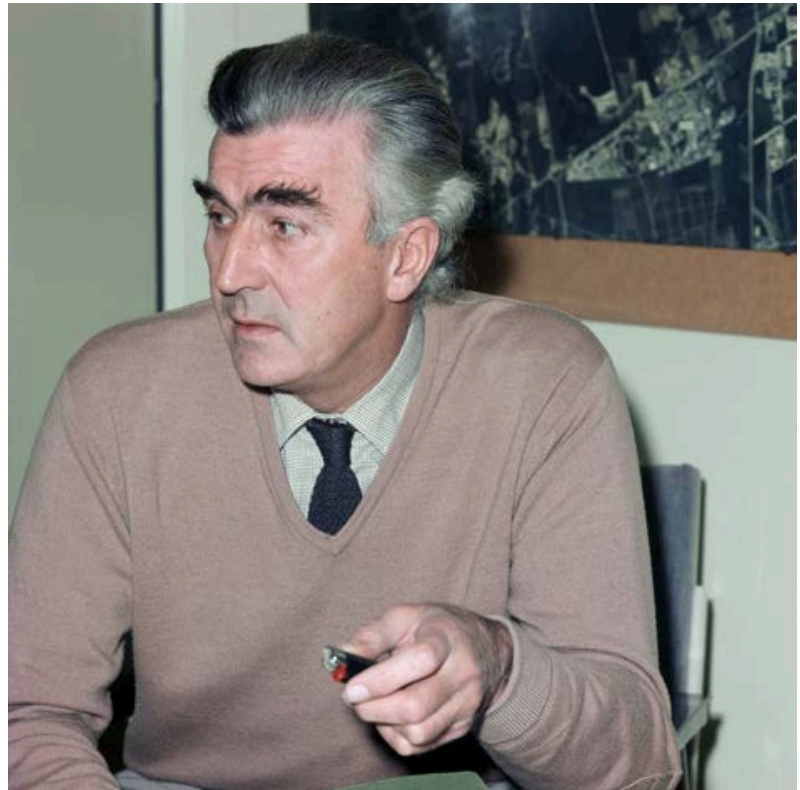

Fig. 11. John Adams at work in 1975.

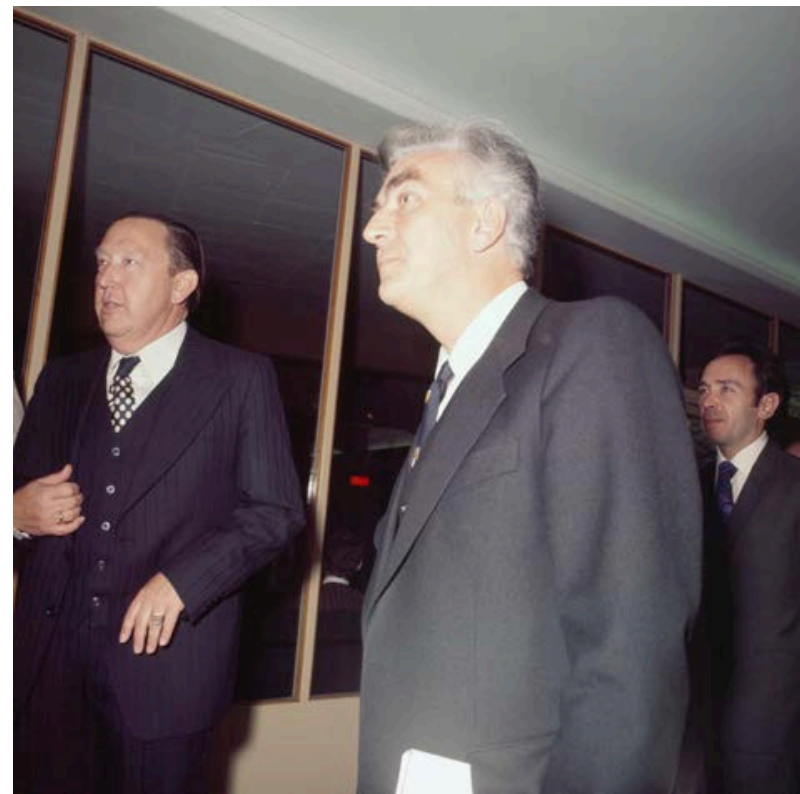

Fig. 12. John Adams with his deputy, Hans-Otto Wüster, on their way to the SPS inauguration ceremony.

purchasing) formed the so-called Parameter Committee, which was in fact the management structure for the project [4].

John, who was also an excellent architect, designed himself the office and laboratory buildings at the new French Prévessin site, about $3 \mathrm{~km}$ away from the Meyrin site. It consisted of four three-floor

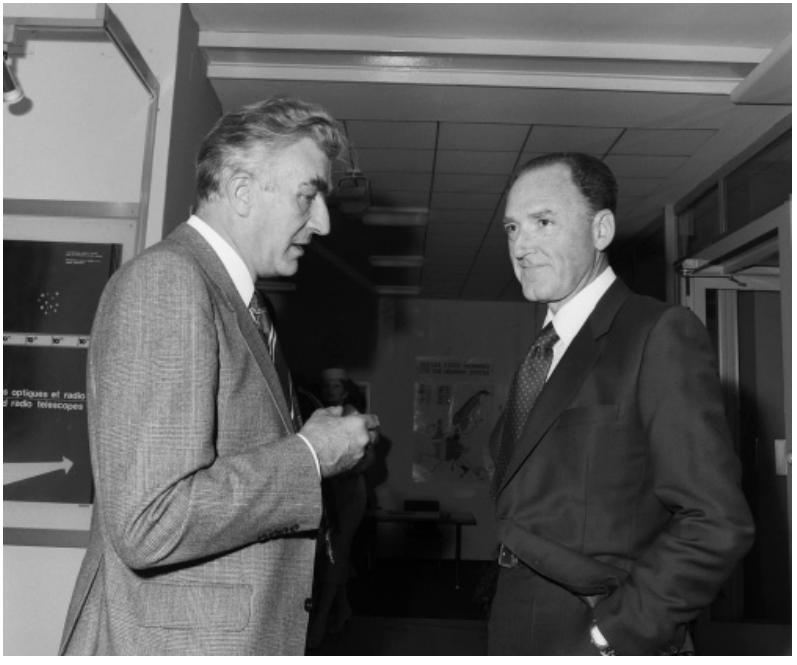

Fig. 13. John Adams with Giorgio Brianti.

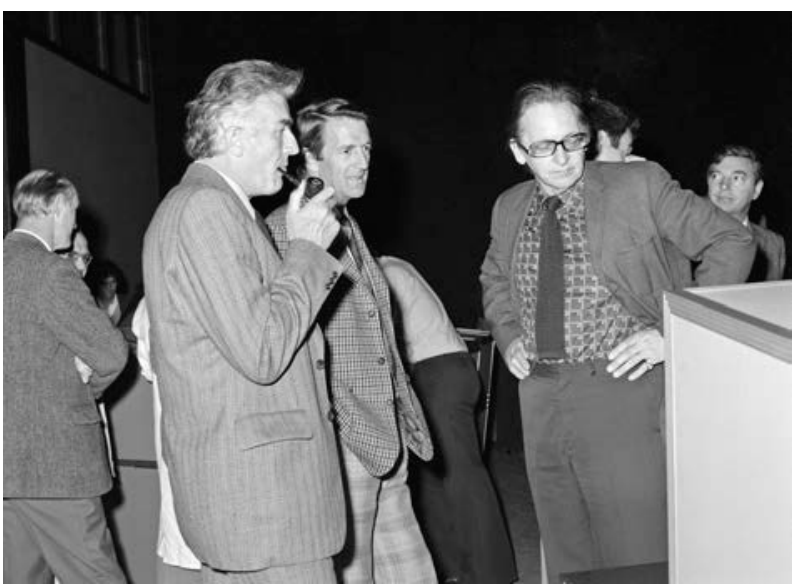

Fig. 14. J. Adams, R. Billinge and M. Crowley-Milling in 1976.

cross-shaped buildings and a large central assembly hall. However, not all people taking part in the program moved to Prévessin; John had the wisdom not to duplicate all functions by making use of some services of Laboratory I. I had mixed feelings concerning this new site. If, on one hand, it strengthened the team spirit for the realization of the project, on the other hand it provoked a certain separation among the staff of the two CERN laboratories.

In addition to the weekly Parameter Committee meeting, John ran the project with another weekly meeting on civil engineering, with variable participation according to the subjects. Of course, the civil engineering was very important not only for the novel aspect of the deep underground work, but also 
because John was convinced that strict control of it, with the aim of minimizing surfaces and volume, would be one of the best ways to limit expenditures. Facing John during this type of meeting was quite an experience. The person presenting the request of a given civil engineering work had to defend its need down to almost the last cubic centimeter! John challenged how solid and justified the request was by looking the defender firmly in the eyes, putting a lot of questions and sometime proposing alternatives. At the end, if the defender came out with a success, even if partial, he could be sure to have worked for the benefit of the project.

Another facet of the effectiveness of John's project direction was to follow very closely with his own eyes not only the paperwork, but also the realization in terms of models, prototypes and, above all, civil engineering progress. He was aware of every detail. When Robert Lévy-Mandel took him around the site, usually on Saturday, he often realized that John already knew everything. The tunnel boring was completed in 1974 (Fig. 15), to the delight of all.

Coming back to technicalities, the project departed from previous CERN machines in a number of components. One was the very compact magnets with coils insulated by glass fiber impregnated with epoxy resin, but without the customary extra layers of mica used for all other previous CERN magnets.

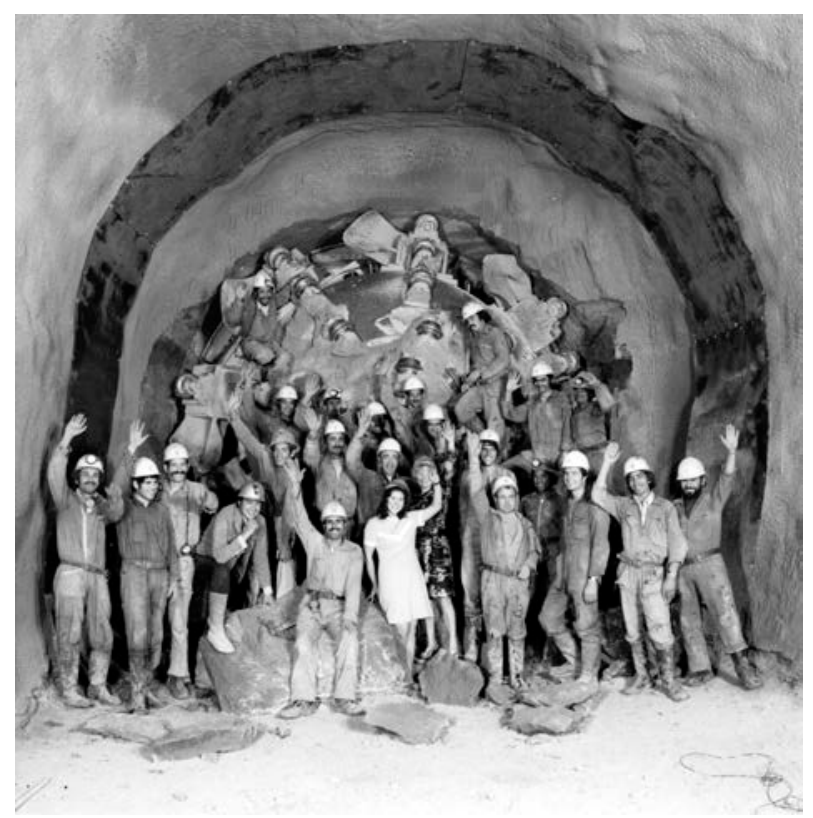

Fig. 15. Completion of the SPS tunnel excavation in 1974.
Roy Billinge's idea was that this simplified insulation was not only sufficient but enabled the uncovering of fabrication faults. The aperture of the vacuum chambers was also considerably reduced with respect to the previous project by reducing the space allowed for orbit distortion, alignment and magnet errors and counting on orbit correction after the first turn. Hence the magnet cross-sections were notably smaller compared to previous projects.

Models and prototypes confirmed the soundness of the solution but, when the fabrication was already well advanced, a number of magnets already installed in the tunnel showed defective coil insulation. This was a big blow, with the fear of repeating at CERN the FNAL problems [3]. The novel type of insulation was thought to be responsible and all kinds of theories explaining the accident were formulated, until Roy himself found out that, in the factory, the coil ends were cleaned with phosphoric acid, which damaged the insulation. This concerned in total 280 magnets. An emergency program was established to restore the situation and, in the end, this incident had little or no effect on the date of completion of the machine. During the entire crisis, called the "black January," John remained extraordinarily calm, with no reproaches or accusations toward anybody - a distinctive mark of his superior quality as a leader and a manager. Another very important area where the project was very innovative was the control system, the task of Michael Crowley-Milling, based for the first time on a distributed network of computers and on innovative equipment for the control desk.

A view inside the newly completed tunnel is shown in Fig. 16.

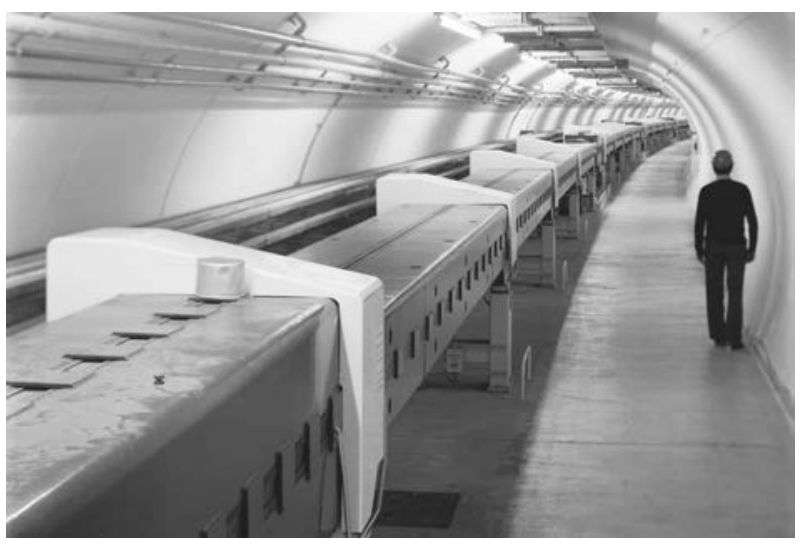

Fig. 16. The SPS ring in 1976. 
It is also worth mentioning that during the construction some pressure was felt from external laboratories to adopt the "missing magnet" scheme, namely to install initially only one half of the classical room temperature magnets and eventually use superconducting magnets to complete the machine. John did not like the idea at all, considering that the risk was too high. Finally, he decided to complete the machine in one go, but asked me to collaborate with Saclay on the design of a superconducting dipole prototype for future use, if not in the machine, for the secondary beams. This successful collaboration was very profitable later for the LHC.

The construction continued with no other major problems and on the morning of 17 June 1976 the beam reached the energy of $300 \mathrm{GeV}$ as defined in the program, enabling John to announce it to the Committee of Council. In the afternoon, during the Council session, John requested permission from the Delegates to go to a higher energy and, having obtained it, finally announced that the energy of $400 \mathrm{GeV}$ had been reached. At that time I thought that this two-step procedure was coquetterie on John's behalf, but indeed some Delegates had wanted to limit the energy, fearing a higher cost [3].

It was during this period that my contact with John became very frequent. What I can say is that, if John's performance was quite remarkable during group meetings, the experience of personal contact with him was also amazing and instructive. When you presented a proposal he looked at you in a very firm way, over his half-spectacles, to assess how convinced you were of the proposal. Then he started to use one of his preferred managerial tools - the pipe. He would take out various small tools from a little bag and begin to carefully clean the pipe. Meanwhile, I am sure, he was weighing carefully in his mind all aspects and consequences of what you said, together with possible alternatives, and when the pipe was properly cleaned, he arrived at the decision or the answer, often absolutely final.

While the SPS was approaching completion, an important managerial decision had to be taken by the Council. The term of office of Willy Jentschke as Director-General of Laboratory I was ending in December 1975, while that of John for Laboratory II extended for another three years. It was generally admitted that the two laboratories had eventually to be reunited either in 1976 or three years later.
The first alternative prevailed, but who should be appointed as Director-General of the reunified laboratory? The obvious choice was John, because of his abilities and international reputation, but there was some reluctance from the community of physicists to accept an "engineer" as Director-General. After many discussions, the final decision was to appoint John as Executive Director-General and Leon Van Hove as Research Director-General for the classical duration of five years (1976-1980). The two newly named Director-Generals, plus the outgoing D-G and the Council President, are shown in Fig. 17. To ease his continuing task for the completion of the SPS, John changed the internal SPS organization by appointing Bas de Raad as Head of the accelerator, Robert Lévy-Mandel for site and general services, and myself for the experimental areas. In 1979, I succeeded M. Crowley-Milling as SPS Division Leader.

My impression is that, for John, this last period of leadership was not the happiest of his life. He was used to being the only captain on the ship and therefore had some difficulties in having to always reach an agreement with Leon on practically all matters of importance, including managerial and administrative issues. However, goodwill prevailed on both sides and, as we shall see, important decisions were taken in those years for the future of CERN.

The SPS era was particularly propitious for advancing international collaboration, a constant theme during John's career at CERN, and indeed an aim pursued by all CERN managements. Already back in 1952, Amaldi spent several hours with John and was impressed by his interest in creating a new

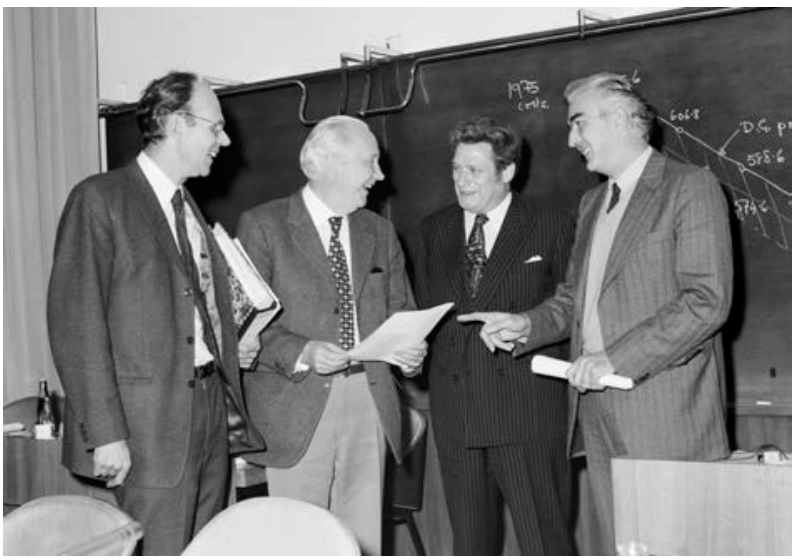

Fig. 17. Van Hove, Jentschke, Levaux (President of the Council) and John Adams in 1975. 
European laboratory [1]. This is all the more remarkable since large nations alone could still undertake ambitious accelerator projects, and not all research physicists supported the idea of a multinational organization.

During the PS construction period, in addition to the close collaboration with the Brookhaven Laboratory mentioned above, first contacts were established with Russian physicists at the International Conference on High Energy Physics in Geneva in 1956. Later on, the PS Division received the first team of Russian physicists at the beginning of the sixties and constructed in 1969 the extraction system for the Serpukhov accelerator, which was the highest energy accelerator at that time [3].

It was during the SPS construction that John developed contacts with China, resulting in an exchange of visits. He was invited to visit China in 1977, and there he was received by the Chinese Premier Teng Hsiao-ping, who at that time made the historical announcement that China would open up to the world and to the use of the best of Western technology [3]. In parallel, a collaboration was established with KEK in Japan in view of the construction of LEP and for the development of superconducting magnets.

Last but not least, the CERN model was at the origin of other European scientific organizations, like ESRO and ELDO, unified later on in ESA (European Space Agency) and ESO (European Southern Organization, for astronomical research in the southern hemisphere). ESO was actually founded at CERN, and had its head-quarters at CERN for a long time.

Concerning space research, the idea of European collaboration dates back to a letter written by Prof. Edoardo Amaldi to Prof. Luigi Crocco in Princeton, dated 16 December 1958. This event was celebrated recently by giving the name Prof. Edoardo Amaldi to the third space Automated Transfer Vehicle (ATV3) of ESA, which was launched on 23 March 2012 in a mission to the International Space Station carrying copies of this famous letter.

\section{SPS Experimental Areas}

John Adams' first major CERN project, the PS, suffered a very late start of the physics research program, through no responsibility of his own. He clearly understood the complexities of performing experiments at high energy machines and, during his first term as Director-General, set up the NPRC (Nuclear Physics Research Committee) to oversee the experimental program. Learning from this regrettable experience, he encouraged every effort to facilitate the rapid start of the SPS physics research program.

To this end, the SPS Experimental Areas Group under the leadership of one of the authors (Giorgio Brianti) provided, from the very outset, a wide range of secondary and attenuated primary beams, which were fully instrumented with detectors for beam tuning, particle identification and beam spectrometry. John particularly appreciated the provision quite exceptional at the time - of standardized but state-of-the-art instrumentation which avoided much duplication of effort and which would have been a headache to maintain and to accommodate in the beam lines had there been many different types of devices.

A West Area Preparation Committee was set up well before the first beam, in order to inform users about the facilities and infrastructures and how to use them. Liaison physicists helped to install the experiments, and the group provided many other services (e.g. gas supplies, drawing office, power supplies). In order to ensure that the facilities were in line with the needs of the users, John appointed James Allaby, a member of the Experimental Physics Division, as SPS Physics Coordinator.

This part of the report will describe very briefly the facilities as initially installed for the first round of SPS experiments; more details can be found in App. A.

\subsection{Beam instrumentation}

The beamlines were well equipped with the basic instrumentation required for beam tuning and diagnostics, including scintillator counters, analog wire chambers for measurement of beam position and size, and scintillator filament scanners to optimize the beam divergence. All were remotely removable from the beam to limit multiple Coulomb scattering.

Momentum measurements of individual beam particles were provided by four digital wire chambers, arranged in pairs surrounding beam magnets [11].

Particle identification was provided by a combination of threshold Cerenkov and CEDAR 


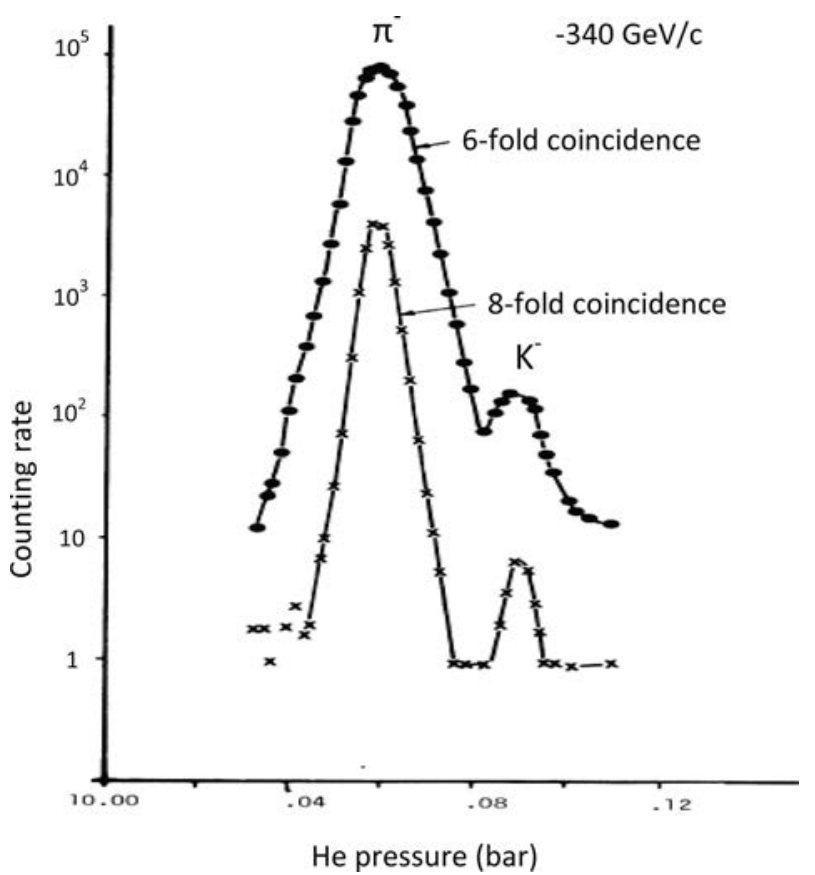

Fig. 18. Pressure curve for a CEDAR-N, showing good separation between $\pi^{-}$and $\mathrm{K}^{-}$at $340 \mathrm{GeV} / \mathrm{c}$.

(CErenkov Differential with Achromatic Ring focus) counters [12]. Figure 18 presents a pressure curve for a North Area CEDAR, showing good separation between $\pi^{-}$and $\mathrm{K}^{-}$at $340 \mathrm{GeV} / \mathrm{c}$.

\subsection{West experimental area}

This existing area was the first to come into operation. The primary proton beam was split into three parts at the level of the West Area, but was limited in energy to $250 \mathrm{GeV} / \mathrm{c}$ due to the background muon dose rate at the CERN fence downstream of the area.

A large number of experiments were already installed before the first extracted SPS beams became available in late 1976 .

\subsection{North experimental areas}

Physicists eagerly awaited the higher energy beams planned for the North Areas. Unlike the West Hall, the North Experimental Area buildings and the transfer tunnels leading from the SPS to the target areas had to be conceived, designed, constructed and equipped with all the necessary infrastructure. Beamlines were commissioned in accordance with the priorities of the physics program and the readiness of the experiments to set up and take data.
The first area to receive beam was EHN2 (Experimental Area North 2) in early 1978, housing two muon experiments. Shortly after, also in 1978, the beams to the large experimental hall EHN1 (Experimental Hall North 1) came into operation, serving nine experiments.

Two years later, there followed two beams in the shielded, underground high intensity facility ECN3 (Experimental Cave North 3) [13], where two large experiments were installed.

\section{Further Developments}

\subsection{SPS as proton-antiproton collider}

During the period 1976-1980, John set up the "Accelerator Club," where the foremost accelerator experts of the Laboratory met regularly to discuss improvements to the existing machines and ideas for new developments. The most interesting one was to use the SPS as a proton-antiproton collider, an idea put forward very strongly in 1976 by Carlo Rubbia [5]. This required having proton and antiproton beams of comparable intensity, constituting the major problem to be overcome. The only way forward was to produce antiprotons by the $26 \mathrm{GeV}$ protons of the PS (a production rate of one antiproton for one million protons) and then store them in an accumulator ring prior to their injection into the SPS. Like all storage rings, the accumulator ring had limited acceptance in the three dimensions, whereas the antiprotons emerging from the target had a large spread in production angles and momentum. The only solution was to concentrate the beam by either electron or stochastic cooling. Since stochastic cooling had been invented by Simon van der Meer [8] in 1972 and tested successfully in the ISR in 1974, the proposal was based on this method.

Van der Meer's original report on stochastic cooling was published in 1972 and the first successful tests were conducted in the ISR in 1974 and in 1976 by him and various other people, among them $\mathrm{W}$. Schnell and L. Thorndahl. In the same period, ideas were put forward for the accumulation of antiprotons in storage rings by D. Möhl, P. Strolin and L. Thorndahl, and independently by P. MacIntyre. A similar proposal was made at Fermilab again by C. Rubbia, D. Cline, P. MacIntyre and F. Mills [5].

Modifications to the SPS were also needed, including the insertion of low beta sections around 
the collision points, a significant decrease in the vacuum pressure and, of course, the construction of huge (for the time) underground experimental areas for mobile experiments (UA1 on a platform, UA2 on air cushions). The mobility of these experiments in and out of the SPS ring was necessary in order to allow periods of fixed target operation at least once a year.

Leon Van Hove, the Research Director-General, supported the project from the beginning, while the accelerator community was initially skeptical, but was eventually won over after further feasibility studies were made, and by the prospects of undertaking a very challenging enterprise. Prior to the final design of the Antiproton Source, a test synchrotron called ICE (Initial Cooling Experiment) was quickly assembled by G. Petrucci using the refurbished magnets of the g-2 experiment in order to test both electron and stochastic cooling. The stochastic cooling method obtained a brilliant confirmation. A committee chaired by F. Bonaudi finalized the accelerator project.

The scheme consisted in using the PS at the maximum beam intensity concentrated over one quarter of the circumference, in order to match the circumference of the Antiproton Accumulator (AA). This was obtained by extracting the beam from the Booster in 10 bunches, instead of the usual 20 , by recombining vertically the bunches of pairs of Booster rings, and by further reducing the 10 bunches to 5 in the PS by RF gymnastics. The beam was then extracted from the PS at $26 \mathrm{GeV}$ and directed to the target at the entrance of the AA. The antiprotons were collected at $3.5 \mathrm{GeV}$ by a magnetic horn (another important invention of S. van der Meer [8]).

R. Billinge and S. van der Meer [8] directed the design and construction of the AA (Fig. 19). Despite the great sophistication and the number of elements, the ring was constructed and tested successfully in less than three years. The formation of a full antiproton stack took two to three days, or 100,000 PS pulses. A question much debated at the time was what to do with the antiproton stack: direct injection into the SPS at $3.5 \mathrm{GeV}$ or postacceleration in the PS to $26 \mathrm{GeV}$ in order to inject into the SPS above the transition energy. Since there was no agreement among Bonaudi's Committee on this point, John, a convinced supporter of the project after his initial hesitation, took it upon himself to study thoroughly the question and decided in favor of postacceleration of the antiproton beam in the PS [3]. It was a wise decision, which undoubtedly facilitated the reliable operation of the collider. In Fig. 20, John Adams,

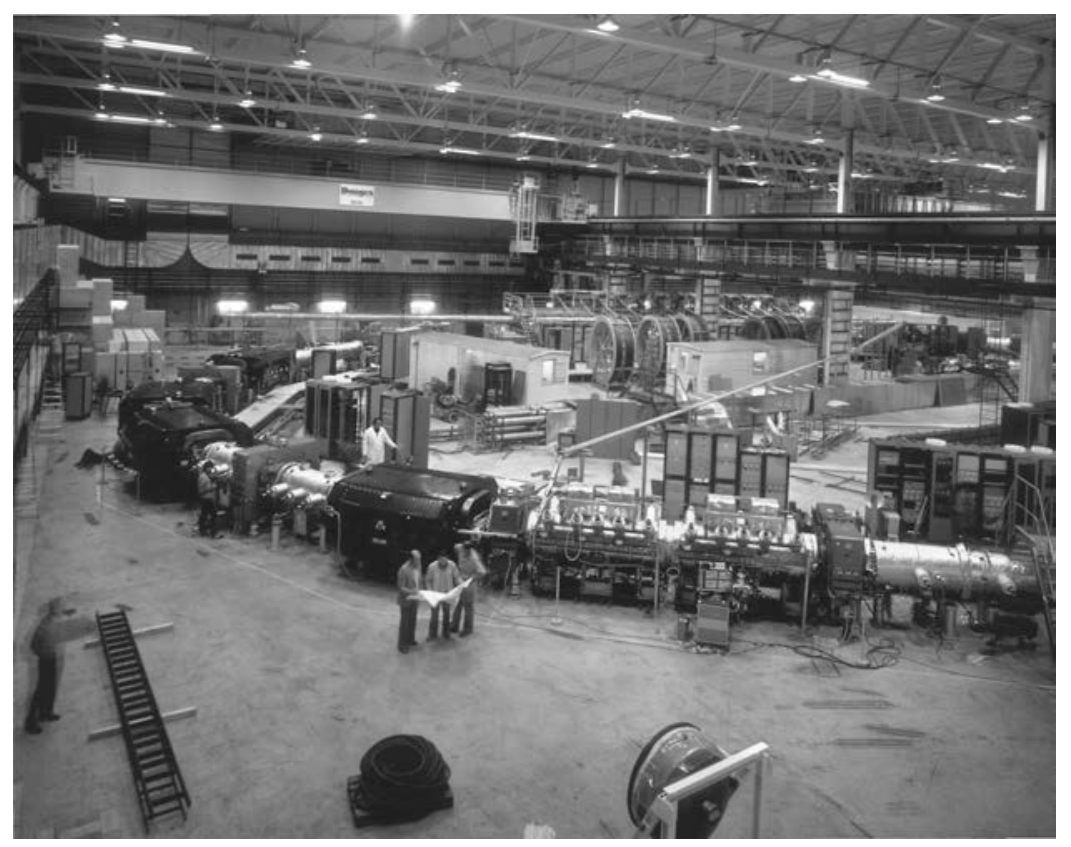

Fig. 19. The Antiproton Accumulator. 


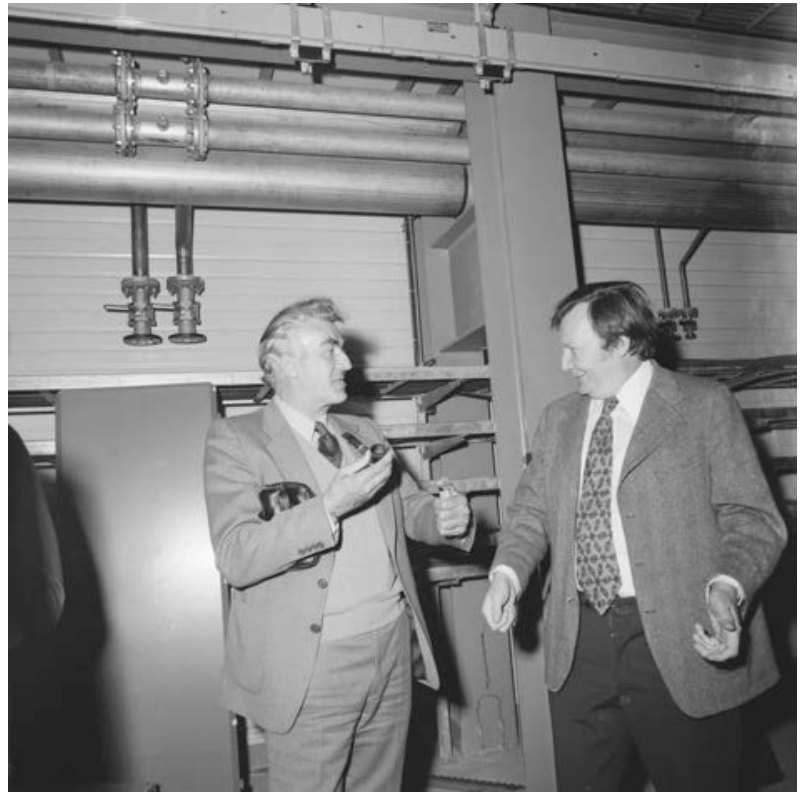

Fig. 20. John Adams and Carlo Rubbia.

equipped with a pipe and associated equipment, and Carlo Rubbia are having an animated discussion.

In 1978 the project was approved, and the first proton-antiproton collisions occurred on 10 July 1981. The first real period of physics exploitation was in 1982, with initial luminosities in the low $10^{29} \mathrm{~cm}^{-2}$ $\mathrm{s}^{-1}$ and an integrated luminosity of $28 \mathrm{nb}^{-1}$ (sufficient for the discovery of W's). The year 1983 saw the collected integrated luminosity increased to $153 \mathrm{nb}^{-1}$ and the discovery of the $\mathrm{Z}$ boson.

A few years later, a substantial improvement of the Antiproton Source was obtained by separating the function of collection and accumulation/cooling of antiprotons. This implied the addition of a second ring (Antiproton Collector, AC) around the original AA. Consequently, the luminosity went well above $10^{30} \mathrm{~cm}^{-2} \mathrm{~s}^{-1}$, the record being $6 \cdot 10^{30} \mathrm{~cm}^{-2} \mathrm{~s}^{-1}$.

Looking back to the early 1980s, one nontechnical but very important fallout of the protonantiproton undertaking was the daily working together of the experimental teams and of the accelerator people. We all remember with nostalgia the animated discussions of the five o'clock meetings in the SPS Control Room to decide the course of action for the following day on the basis of the status of the antiproton stack in the AA. But it worked well in the end!

\section{2. $L E P$}

In 1977 a meeting of ECFA reached the conclusion that the next big project should be an electronpositron collider of at least $100 \mathrm{GeV}$ beam energy. Studies by accelerator experts showed that, in order to reach such a high energy, a ring of about $30 \mathrm{~km}$ would be necessary. Moreover, only the use of superconducting radio frequency cavities would deliver this energy.

John, who was more inclined to a proton machine using superconducting magnets, became convinced that the physicists wanted the electronpositron collider and participated actively in its study with the help of Michael Crowley-Milling, who was then the Directorate Member for the accelerator program. However, John remained of the opinion that a proton machine would be required after LEP and so, in a page of his handwritten notebook of 1977, he advocated a LEP tunnel of a sufficient width $(3.5 \mathrm{~m})$ to accommodate also a proton ring using superconducting magnets of $4.5 \mathrm{~T}$ and a beam energy of $3 \mathrm{TeV}$. He called this SPEC (Super Proton Electron Complex) [14].

A tunnel of $30 \mathrm{~km}$ could be built at CERN, but about one third of it would not be in the good molasse rock but would penetrate the problematic limestone of the Jura mountains, which certainly contained cavities with water at high pressure.

LEP was finally approved in 1981, with Herwig Schopper as Director-General, who called in a wellknown physicist, Emilio Picasso, as Project Leader. Emilio formed a team of experienced accelerator people and was able to mobilize the large required effort throughout the laboratory. In order to minimize the problems of excavation in the limestone, the tunnel circumference was reduced to about $27 \mathrm{~km}$ and the machine plane tilted in order to reduce the maximum depth of access shafts to about $180 \mathrm{~m}$.

The execution of the project does not belong here, because John had no part in it, but I would like to stress his vision of a proton machine in the same tunnel mentioned above. In fact, I started the work on the future Large Hadron Collider already in 1982 with a group of the best CERN experts on a highly part-time basis, since the main effort was concentrated on LEP. Thinking back to that period, I remember with emotion John in the Accelerator Club taking part in the discussion of the initial project, of the next proton machine [6], which was to 


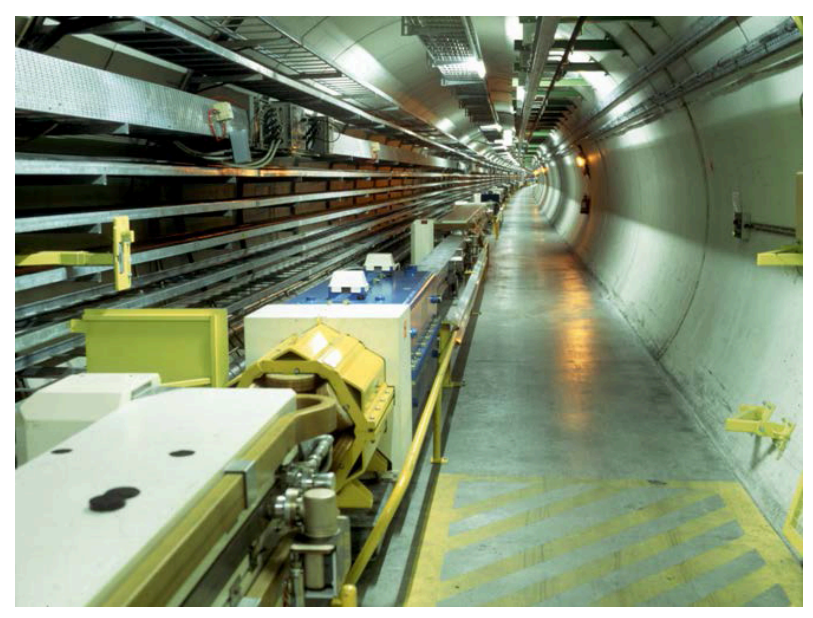

Fig. 21. The LEP collider.

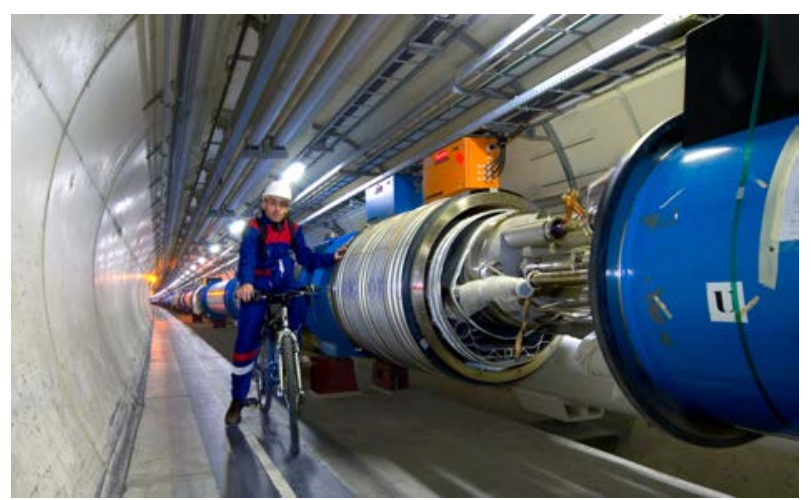

Fig. 22. The LHC collider.

materialize much later as the Large Hadron Collider (LHC)! Installations in the LEP and LHC tunnel are show in Figs. 21 and 22.

\section{Conclusion}

John Adams was an exceptional personality. Without a formal academic education but provided with a wide range of natural abilities, he became an extraordinary engineer and a charismatic leader. In remembering him with emotion, a number of distinctive qualities come to mind, like wide technical knowledge, rationality, organization, vision, authority, capacity of analysis and political abilities. But he was also rather reserved about his deep thoughts, feelings and emotions, so that it is not easy to rank these exceptional natural and developed gifts in a given order. It was a mix of all these qualities which made him an extraordinary engineer, capable of designing and constructing very complex machines involving a wide range of technologies in time and within budget; a charismatic leader, able to assemble, direct and orient international teams toward well-defined goals; and the right man at the right time for launching CERN on the track of a very successful international scientific organization. Later on, he also directed and oriented all other further developments of what has become the foremost laboratory for particle physics. Once, he said that he was very fortunate to have started his professional life at the emergence of three new technologies: radar during the war, accelerators at Harwell and CERN, and controlled fusion at Culham.

Clearly, a combination of fortunate circumstances helped to determine his destiny, but an inkling of his approach to life can be obtained from his statement that "if there are not enough events or they are too infrequent, then they can often be stirred up by various means, but there is no substitute for a clear sense of direction. An aimless person in a sea of random events takes a very long time indeed to reach any goal." [15]

Certainly, John Adams was a person with a mission in life and a "clear sense of direction"; he achieved much more than he, or anybody else, could have expected at the beginning of his professional life. CERN and the entire community of particle physics owe him the long-lasting gratitude due to a founding father.

\section{Acknowledgments}

The authors acknowledge the help of Niels Doble and Lau Gatignon, who provided information about the SPS' early particle beams, and thank Alfredo Placci for his knowledge of the CEDAR devices.

\section{Appendix A. SPS Experimental Areas}

Responding to the demands of the experimental community, intense beams of hadrons, electrons, tagged photons, and muons were provided, including a superconducting RF-separated and a polarized muon beam. A group of liaison physicists, including one of the authors (D. E. P.), designed the beamlines and the layout of the experiments, coordinated their installation, and helped the users profit from the facilities - they also modified the beamlines and layouts as required. 


\section{Appendix A.1. Beam instrumentation}

Both analog and digital wire chambers were provided, the former for beam profiles and the latter for beam spectrometry. Almost all had $1 \mathrm{~mm}$ wire spacing and could give profiles for beam intensities ranging from $10^{4}$ to $10^{11}$ particles/s [16].

Most secondary, and later tertiary, beams were equipped with four digital wire chambers, arranged in pairs surrounding bending magnets, in order to provide momentum measurements for individual particles. A resolution on one pion mass resulted in most cases [11].

Particle identification was provided by threshold Cerenkov and CEDAR counters. Two types of differential Cerenkov counters were provided: CEDAR-W for the West Area, providing $\pi-\mathrm{K}$ separation up to $150 \mathrm{GeV} / \mathrm{c}$, and flagging protons above $12 \mathrm{GeV} / \mathrm{c}$; CEDAR-N for the higher energy North Area, providing $\pi-\mathrm{K}$ separation up to $340 \mathrm{GeV} / \mathrm{c}$ (see Fig. 18) and capable of tagging protons above $60 \mathrm{GeV} / \mathrm{c}[12]$.

The sophisticated optical system of the CEDAR counters consisted of a quartz Mangin mirror (back surface reflection) and a chromatic corrector. Procurement of the Mangin mirror was no easy matter, and Claude Bovet and the team which designed and built the CEDARs profited from the presence on the CERN site of the optical experts from the European Southern Observatory project.

Command of all instrumentation and electronics was under user-friendly computer control, and all the electronics was provided and serviced by the SPS Experimental Areas Group.

\section{Appendix A.2. West Area}

This existing area was the first to come into operation.

Figure 23 is a schematic drawing of the West Area as initially installed. The labels have the following meanings: $\mathrm{T}$ for "target," $\mathrm{H}$ for "hadron," $\mathrm{E}$ for "electron," S for "separated," P for "attenuated proton," Y for "hyperon," $\mathrm{N}$ for "neutrino beams" and WAn for "West Area experiment number 'n'."

A particularly novel feature was the provision of a superconducting- $\mathrm{RF}$ ( $\mathrm{S}$ band)-separated beam to the general purpose $\Omega$ spectrometer.

Note the large number of experiments installed for the start of SPS operation.

\section{Appendix A.3. North Areas}

The first area to be served was EHN2 (Experimental Area North 2) in early 1978, housing two muon experiments. In designing the M2 muon beam [17], special care was taken to avoid the muon halo problem which has troubled the Fermilab beam. A sophisticated muon tracking program, HALO [18], helped to identify technical solutions, and special 5-mlong magnetic collimators and magnetized shielding blocks downstream of the hadron absorber proved to be efficient in limiting the muon halo at the experiment to an acceptable level.

Shortly after, also in 1978, the beams to the large experimental hall EHN1 (Experimental Hall North 1) came into operation. An innovative feature of beams to EHN1 was the introduction of "wobbling stations" [19] in the production target zone, which allowed, for each target, two beams to be produced

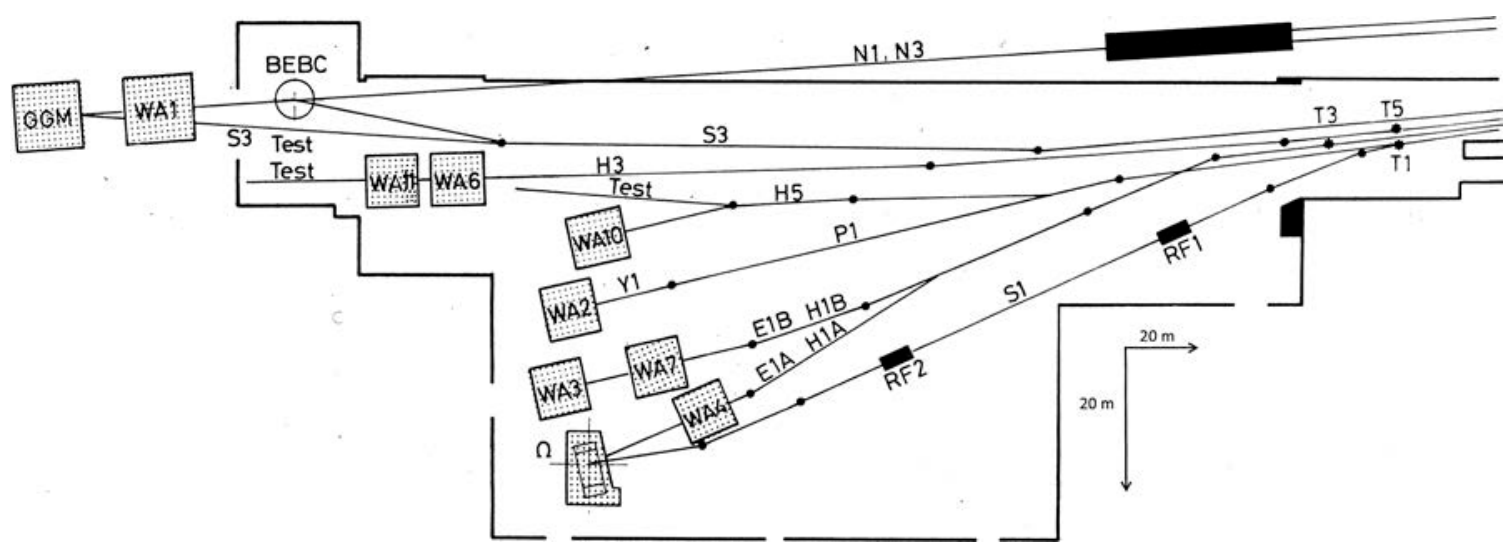

Fig. 23. Layout of the West Area beams and experiments in 1976. Note the different scales in the horizontal and vertical directions. 
Table 1. Characteristics of the North Area beams as initially installed.

\begin{tabular}{|c|c|c|c|}
\hline $\begin{array}{l}\text { Production } \\
\text { target }\end{array}$ & $\begin{array}{l}\text { Experimental } \\
\text { hall }\end{array}$ & Beam & Beam properties \\
\hline $\mathrm{T} 2$ & EHN1 & $\mathrm{H} 2$ & $\begin{array}{l}\text { High energy, high resolution secondary beam, for charged hadrons, electrons, polarized } \\
\text { protons from } \Lambda \text { decay, and attenuated primary protons. Maximum momentum } \\
400 \mathrm{GeV} / \mathrm{c}, \text { momentum acceptance } \pm 2 \% \text {. }\end{array}$ \\
\hline $\mathrm{T} 2$ & EHN1 & $\mathrm{H} 4$ & $\begin{array}{l}\text { High energy, high resolution secondary beam, for charged hadrons, electrons, polarized } \\
\text { protons from } \Lambda \text { decay, and attenuated primary protons. Maximum momentum } \\
400 \mathrm{GeV} / \mathrm{c} \text {, momentum acceptance } \pm 1.4 \% \text {. }\end{array}$ \\
\hline $\mathrm{T} 4$ & EHN1 & $\mathrm{H} 6$ & $\begin{array}{l}\text { High energy, secondary beam, for charged hadrons. Maximum momentum } 200 \mathrm{GeV} / \mathrm{c} \text {, } \\
\text { momentum acceptance } \pm 1.5 \% \text {. }\end{array}$ \\
\hline $\mathrm{T} 4$ & EHN1 & $\mathrm{H} 8$ & $\begin{array}{l}\text { High energy, high resolution secondary beam, for charged hadrons, electrons and } \\
\text { attenuated primary protons. Maximum momentum } 400 \mathrm{GeV} / \mathrm{c} \text {, momentum } \\
\text { acceptance } \pm 3 \% \text {. }\end{array}$ \\
\hline T6 & EHN2 & M2 & $\begin{array}{l}\text { Muon beam-high backward/forward polarization for } P_{\mu+} \approx 0.9 / 0.6 P_{\pi+} \text {. Maximum } \\
\text { momentum } 300 \mathrm{GeV} / \mathrm{c} ; \text { momentum acceptance } \pm 10 \% \text { for parent particles, } \pm 6 \% \text { for } \\
\text { muons. }\end{array}$ \\
\hline $\mathrm{T} 8$ & ECN3 & H10 & $\begin{array}{l}\text { Intense } \pi \text { beam, up to } 10^{10} \text { pions/pulse. Maximum momentum } 400 \mathrm{GeV} / \mathrm{c} \\
\text { momentum acceptance } \pm 12 \% \text {. }\end{array}$ \\
\hline $\mathrm{T} 10$ & ECN3 & E12 & $\begin{array}{l}\text { Broadband (momentum acceptance } \pm 28 \% \text { ) } e^{-\gamma} \text { beam. Maximum momentum of } e \\
\quad 300 \mathrm{GeV} / \mathrm{c} \text {. }\end{array}$ \\
\hline
\end{tabular}

at zero or very small production angles, with only loose coupling in their momenta.

Fierce radiation levels prevailed in the West and North Area target regions. To limit the effects of radiation damage the bending magnets immediately downstream of the targets were equipped with mineral insulated (high alumina concrete), radiationresistant coils [20], and the upstream quadrupoles were installed on "plug-in" bases which assured automatic alignment, powering and cooling of replacement elements.

Characteristics of the North Area beams, as initially installed, are summarized in Table 1.

\section{References}

[1] E. Amaldi, John Adams and his times. First John Adams Memorial Lecture, CERN 86-04.

[2] E. J. N. Wilson, Sir John Adams: His legacy to the world of particle accelerators. J. Adams Memorial Lecture 2009, CERN-2011-001.

[3] M. Crowley-Milling, John Bertram Adams, Engineer Extraordinary: A Tribute, Gordon and Breach Science (1993).

[4] M. Goldsmith and Edwin Shaw, Europe's Giant Accelerator, Taylor and Francis (London, 1977).

[5] R. Cashmore, L. Maiani and J.-P. Revol, Prestigious Discoveries at CERN, 1973 Neutral Currents, 1983 $W$ \& $Z$ Bosons (Springer) — G. Brianti, CERN's contribution to accelerators and beams (pp. 25-40).

[6] Large Hadron Collider in the LEP tunnel: Proc. ECFA-CERN Workshop CERN 84-10 (Mar. 1984).
[7] E. D. Courant, M. S. Livingston and H. S. Snyder, Phys. Rev. 88, 1190 (1952).

[8] V. C. Chohan, Simon van der Meer (1925-2011): A modest genius of accelerator science, Rev. Accel. Sci. Technol. 4, 279 (2011).

[9] CERN Courier, Vol. 53, archive page 14 - The $300 \mathrm{GeV}$ project.

[10] J. B. Adams, The European $300 \mathrm{GeV}$ accelerator, in Proc. 8th Int. Conf. on High-Energy Accelerators (CERN, Geneva, Switzerland, 1971), pp. 25-31.

[11] G. Dubois, A. Placci, L. Pregernig, M. Rabany, B. Skalli and G. Vismara, IEEE Trans. Nucl. Sci. 25(1), 808 (1978).

[12] C. Bovet, R. Maleyran, A. Placci and M. Placidi, IEEE Trans. Nucl. Sci. NS25, 572 (1978).

[13] G. Brianti and N. Doble, The SPS North Area High Intensity Facility: NAHIF. CERN/SPS/EA 77-2, CERN/SPSC/77-72, SPSC/T-18 (1977).

[14] J. Lawson and G. Brianti, 50 years of synchrotrons. 12th J. Adams Memorial Lecture, CERN 97-04.

[15] J. B. Adams, "Take a risk" in "Letters to a Young Scientist," New Scientist 45, 2 (1970).

[16] P. Dreesen and G. Vismara, Nucl. Instum. Methods 156, 325 (1978).

[17] R. Clifft and N. Doble, CERN/SPSC/74-12 (CERN/Lab. II/EA/74-2).

[18] C. Iselin, HALO, a computer program to calculate muon halo. CERN 74-17.

[19] H. Atherton, G. Brianti and N. Doble, Towards a layout of the $300 \mathrm{GeV}$ North Experimental Area. CERN/Lab. II/EA/72-1 (July 1972).

[20] R. L. Keizer and M. Mottier, Mineral insulated magnets. CERN/SPS/EMA/77-3, presented at 6th Int. Conf. Magnet Technology (Bratislava, 1977). 
Giorgio Brianti was appointed directly by Prof. E. Amaldi and spent his whole professional career at CERN from 1954 to 1995 . He took part in the construction of PS from 1954 to 1959 and was Head of the PS Operation Group from 1960 to 1964 . He was also leader of the Synchro-cyclotron Division from 1964 to 1967 of the Synchrotron Injector (Booster) Division from 1968 to 1972; Head of the SPS Experimental Areas Group from 1972 to 1978; Leader of the SPS Division from 1979 to 1980; Director from 1981 to 1993 in charge of accelerators, proton-antiproton collider and preparation of the LHC project.
David E. Plane earned his $\mathrm{PhD}$ on the 10-inch hydrogen bubble chamber at the Liverpool synchrocyclotron, following which he moved to CERN. After working on hyperon resonances and fits to baryon decay rates within $\mathrm{SU}(3)$ and $\mathrm{SU}(6)$, he joined the SPS project which was under the leadership of John Adams. In the mid-1980s he returned to CERN's Research Sector where he joined OPAL, a LEP experiment. In 1998 he became spokesman of the experiment. He was awarded the Rutherford Medal of the UK Institute of Physics, and elected Fellow of the Institute. He is also a member of the Bologna Academy of Science. Retired, he is currently an Honorary CERN Staff Member. 